\title{
Promoting business/IT fusion: an OD perspective
}

\author{
Nina Evans, Department of Business Applications and IT Management, Tshwane \\ University of Technology, Irene, South Africa \\ Crystal Hoole, Department of Human Resource Management, University of Pretoria, \\ Pretoria, South Africa
}

\begin{abstract}
Purpose - It is generally accepted that new information technologies are an integral part of most forms of business initiatives. Evidence suggests that many of these innovations are ineffective and under-utilised. The information systems/information technology (IS/IT) industry often does not seem to be capable of delivering what business clients expect. Owing to this "expectation gap" and various behavioural issues, business experts have a negative perception of the IS/IT function. It is proposed that a new way of alignment between IT and business is necessary The research aims to address two problems, namely, what factors are influencing business-IT interface within organisations, and how the IT executive could contribute towards fusion fulfilling an organisational development (OD) role.
\end{abstract}

Design/methodology/approach - A triangular and qualitative research approach was followed, including a literature study, questionnaire and interview.

Findings - Results indicated a number of reasons leading to IT/business failure and also indicate how fusion can be created by fulfilling an OD role.

Research limitations/implications - Only companies in the Gauteng region, which is considered to be the economic heart of South Africa, have been included in the study. The small sample size might hinder the generalisation of the results and could be further extended.

Originality/value - The research indicates how a healthy business-IT interface can be achieved through the fusion of the IT function and the rest of the business by integrating OD initiatives.

Keyword(s):

Communication technologies; Information systems; Organizational development; Senior management.

\section{Introduction}

Information technology/information systems (IT/IS) do not exist in isolation, but are used in social and organisational contexts. Although it is generally accepted that the new ITs are integrally part of most forms of commercial, industrial and governmental initiatives, evidence suggest that many of these innovations are ineffective and under-utilised. The IS/IT industry often does not deliver what businesses expect of it, resulting in an "expectation gap" and various human behavioural issues. According to one study that involved 45 leading researchers and consultants and 14,000 user organisations - between 80 per cent and 90 per cent of IT investments do not meet their performance objectives. They are either over budget, over time or do not meet the technical specifications. 
Organisations are also lacking an integrated approach to organisational and technical change and often do not successfully attend to the non-technical, i.e. the human and organisational aspects of changing technology.

Many of the problems facing IT departments are neither technical nor fiscal, but managerial and organisational. IT executives are often unaware of the many human and organisational factors to which project failure can be attributed. According to Mann (2002), factors such as the difference in perception between IT and business; ownership struggle, cultural differences, different future perspectives; ineffective communication, credibility issues, relationship and interaction problems and lack of recognition contribute to widening the gap. These viewpoints are supported by other authors such as Aggarwal and Rezaee (1996), Kunda and Brooks (2000), Travis (2002), Fielding (2002) and Riggle (2002). They do not have a holistic perspective on IT-related organisational change and organisational issues. It is widely felt that there is little consideration for the nontechnical issues such as user needs and business strategies, that they are not well understood, that their importance is under-estimated and that action in this area is underresourced (Wynekoop and Walz, 1999; Nielsen et al., 1999; Sawyer et al., 1998; Whittaker, 1999; Riggle, 2002). According to King (1998) there is much evidence that organisational issues are not properly addressed during the systems development processes.

Not so long ago, organisations following the traditional alignment model asked "How do we use technology to help us do what we do? How do we maximise the value of IT to enhance business performance? How do we make sure that IT becomes part of the strategy and not just a response mechanism”? Establishing a relationship between business and IT was therefore traditionally done through "strategic alignment": set the business strategy and then determine how technology can help. Recent viewpoints are that traditional alignment approaches increase risk and prevent organisations from exploiting opportunities (Dickson and DeSanctis, 2000; Smaczny, 2001). Instead of promoting business growth, IT often inhibits it. To solve the problems in the fastchanging environment of today, it is proposed that a successful business-IT relationship can only be achieved through "a higher degree of strategic alignment", namely the fusion of business and IT. According to the Oxford Dictionary, fusion means: " A merging of divorced, distinct, or separate elements into a unified whole”. Such fusion between IS/IT and business should be achieved on the strategic, tactical and operational levels.

\section{Organisational development}

Organisational development (OD) is "a system-wide application of behavioural science knowledge to the planned development, improvement and reinforcement of the strategies, structures and processes that lead to organisational effectiveness" (Cummings and Worley, 2001). OD applies to the processes, strategies and structures of the entire system, such as an organisation or a department within an organisation (for example the IT department). The purpose of OD is to improve organisational effectiveness and create an organisation that can solve its own problems, is capable of high performance and provides a high quality of work life. 
In the past, research has focused on OD, but mostly from the viewpoint of the internal or external OD consultant, providing professional services - diagnosing problems, developing solutions and helping to implement them. However, according to Doyle (2002) the role of the change agent, who aids OD and transformation, is changing beyond the single individual "to encompass a more diverse, multi-functional, mixed status cast of characters”. These people have to combine OD responsibilities with their operational, professional or technical roles. According to Cummings and Worley (2001) functional managers cannot deny their responsibility toward OD. According to McNamara (1999) OD must now focus as much on processes between the parts of the organisation as on the parts themselves. Understanding and fulfilling the OD role would greatly counter the typical problems experienced that are caused by the IT-business gap because it directly addresses the issues contributing to the gap in the first place. Just as OD looks at the organisation from a holistic and integrated point of view, business and IT should be fully integrated (Eckhouse, 2002; Fielding, 2002; Logan, 2002).

To achieve a successful transformation from a state of non-fusion to fusion, the strategy should involve more than just cutting costs, increasing return on investment, or restructuring the business (business reengineering). The process must be driven and implemented throughout all the layers of the organisation through a top-down and bottom-up process. Where necessary, core values, attitudes and the embedded organisational culture needs to be analysed, changed and aligned and steps need to be taken to bridge the differences (Logan, 2002). Correia (2002) states that the solution lies in better management and not merely in designing better tools.

Failure to invest in and integrate OD initiatives and IT will block effective change in many organisations. O'Connor and Smallman (1995) noted that "capitalizing in IT requires something more fundamental than merely changing a corporation's structures, business processes and strategy". They must change what they do, how they do it, how they work with each other, how they work by themselves.

To build a healthy IS/IT department and to contribute towards a healthy organisation is the task of the IT executive. A holistic view, expertise and judgment in social, technological and systems theory and practice are required on all levels in the organisation (McKendrick, 2000; Doyle, 2002; McClenahen, 2002). Kunda (2001) includes the motivation and level of enthusiasm of IT personnel, interactions and communication, organisational resources and support, cognitive skills of all stakeholders and organisational culture in his list of factors influencing IT project success and a positive business-IT relationship. According to Appelbaum (1997) “integrating organisational development and technological intervention into a total system is one of the more difficult tasks for an executive or consultant to execute". One possible solution to the problem is through the implementation of "soft systems" - which are more participative, integrative, socio-technical methods - such as OD. 


\section{The research}

\section{Purpose of the research}

The purpose of the research was to address the following research problems:

1. What are the factors influencing business-IT interface within organisations?

2. How could the IT executive contribute towards fusion fulfilling an OD role?

\section{Research methodology}

To identify the factors influencing business-IT interface and to determine how fusion through an OD role can be achieved, a qualitative approach was decided on. Since the general shift in IS/IT research, away from technological to managerial and organisational issues, there has been an increasing interest in qualitative research in this field. In line with the role of the qualitative researcher, as described by Miles and Huberman (1994), the researcher's role in this project was to:

- gain a holistic overview of the business-IT interface;

- capture data pertaining to the perceptions of local actors "from the inside";

- isolate certain themes and expressions but maintain them in their original forms throughout the study; and

- explicate the ways people in the business-IT relationship understand, account for, take action and otherwise manage their day-to-day situations.

The analysis of the qualitative data consisted of the "discovery of regularities, patterns and themes and the comprehension of the meaning of text or action" (Miles and Huberman, 1994) and coding them into meaningful interpretations.

\section{Research design}

The research consisted of three parts: Part one and two focused on the first research question and part three focused on the second research question:

1. The first part investigated the factors influencing the business/IT interface within organisations to determine the major reasons for the "expectation gap” between business clients and the IS/IT function (i.e. non-fusion). The most important reasons for the business-IT relationship gap, the importance and nature of interpersonal relationships from an organisational behaviour viewpoint and the major reasons for non-fusion were determined from literature and subsequently summarised.

2. The industry's perception of the gap was then determined by gathering and collating information from the leading experts working in this field, who have widespread experience of working with large numbers of user organisations. The aim was to provide findings on a scope and scale from which valid conclusions could be drawn. This strategy was selected to complement findings from the 
existing body of knowledge. A questionnaire, consisting of the elements as identified in the literature study, was designed to determine the industry perception of the significance of each category. The questionnaire was completed by IT and business managers/experts in randomly selected companies in Gauteng, South Africa. The sample consisted of 67 IT managers and 48 business managers from 67 randomly chosen companies in Gauteng, South Africa. A five-point Likert scale was used to indicate the significance of the various issues, ranging from "very significant" to "not significant at all". The questionnaire was used to guide discussions during follow-up personal interviews. The comments made by the participants are reported in conjunction with the questionnaire data.

3. The results of the survey was then used to determine the responsibilities of an IT executive towards promoting business-IT fusion and the possibility to bridge the gap through applying OD principles.

The results of the survey were then used to determine the role of the IT executive towards promoting fusion.

\section{Results}

The first research question was concerned with identifying the factors influencing the business-IT interface from the literature and then verifying it from an industry perspective. Reasons for IT project failure and the poor business-IT relationship were identified and classified into 25 categories, namely:

1. The real business need is not understood and documented - ineffective requirement specification (Correia, 2002; Aggarwal and Rezaee, 1996; Riggle, 2002; Whittaker, 1999; Mann, 2002).

2. Project scope changes (changing business needs/technology) (Aggarwal and Rezaee, 1996; Correia, 2002; Whittaker, 1999; Callon, 1996).

3. Insufficient client expectation management (Mann, 2002; Murray, 2001).

4. Lack of communication (Mann, 2002; Whittaker, 1999; Callon, 1996; Fielding, 2002).

5. Poor documentation practices (Riggle, 2002; Aggarwal and Rezaee, 1996).

6. Testing (Murray, 2001; Aggarwal and Rezaee, 1996).

7. People-, behavioural and cultural issues (Mann, 2002; Logan 2002; Cormack, 2001).

8. Adverse interpersonal relationships (Mann, 2002; Katz and Tucker, 1995).

9. Lack of business ownership/collaboration (Mann, 2002).

10. Lack of shared goals (Kunda, 2001; Logan, 2002).

11. Negative attitude towards the IS/IT function (Logan, 2002; Patching and Chatham, 1998).

12. Lack of strategic alignment (Smaczny, 2001; Dickson and DeSanctis, 2000; Henderson, 1998; Britt, 2002).

13. Strategic role/involvement of IT manager (Eckhouse, 2002; McClenahen, 2002).

14. Skills, attributes and attitudes of IT personnel (Whittaker, 1999; Kunda, 2001; Fielding, 2002; Coghlan and Hurley, 1996). 
15. Lack of shared responsibility (Travis, 2002; Murray, 2001).

16. Insufficient equipment and infrastructure (Murray, 2001; Aggarwal and Rezaee, 1996).

17. Lack of senior management involvement (Travis, 2002; Whittaker, 1999; Murray, 2001).

18. Lack of knowledge transfer between IT and the business (Riggle, 2002; Travis, 2002; Trauth et al., 1993).

19. Different measures of success.

20. Management issues (Kunda, 2001; O'Connor and Smallman, 1995; Wang, 1995).

21. IT management issues (Correia, 2002; Coghlan and Hurley, 1996; Whittaker, 1999).

22. Project-specific issues (Callon, 1996).

23. Project management issues (Whittaker, 1999; Fielding, 2002; Travis, 2002; Aggarwal and Rezaee, 1996).

24. Project manager issues (Whittaker, 1999; Murray, 2001).

25. Finances (Whittaker, 1999).

\section{Survey results}

To determine whether the industry supported the factors identified in the literature, respondents were asked to complete a survey. The survey asked respondents to rank the factors as identified in the literature in order of importance. The respondents subsequently identified the ten most significant of the 25 categories and ranked them from most significant (1) to least significant (10). The following categories were ranked 1 to 5 by the largest percentage of respondents:

1. IT managers:

o lack of communication;

o lack of strategic alignment;

o people issues/behavioural issues/cultural issues;

o strategic role/involvement of IT manager;

o skills, attributes and attitudes of IT personnel;

o lack of knowledge transfer between IT and business;

o negative attitude towards the IS/IT function;

o adverse interpersonal relationships;

o project manager issues; and

o management issues: IT management.

2. Business managers:

o lack of communication;

o lack of knowledge transfer between IT and business;

o lack of strategic alignment;

o people issues/behavioural issues/cultural issues;

o negative attitude towards the IS/IT function;

o skills, attributes and attitudes of IT personnel;

o strategic role/involvement of IT manager;

o project manager issues; 
o adverse interpersonal relationships; and

o management issues: IT management.

\section{Interview results}

To investigate further the reasons for lack of fusion in the business-IT function in organisations and to determine if there were any additional factors not mentioned in literature, personal interviews were used to gain more in-depth knowledge.

A problem that was perceived with respect to top management is that they do not really see IT professionals as real people. ("They don't treat them as humans.”) The business department sees IT as a never-ending drain on the bottom line that is fighting against the business. "Business and IT people don't work together constructively." This is supported by the views of authors such as Mann (2002), Logan (2002) and McCormack (2001) who noted that relationship issues between IT and the rest of the organisation are often the cause of miss-alignment and IT not meeting business needs.

Insufficient skills and training and the lack of recognition of each other's capabilities were mentioned as major concerns. It seems as if business executives and IT both have insufficient knowledge in terms of what the other is capable of (Riggle, 2002; Eckhouse, 2002). Business executives know IT can make a difference but they are not sure how (Britt, 2002). Britt (2002) also noted that a different mindset is required for both IT and business and that they must feel comfortable crossing over to each other's domain, valuing their respective contributions and giving each other recognition.

The lack of knowledge inside the organisation also causes many conflicts, as does the fact that they do not really operate entirely as a team:

The IT manager doesn't in fact take up the position to fill the gap between IT and business.

Some of the respondents also felt that part of the problem was that the IT manager/CIO does not serve on the executive committee and cannot directly impact on strategy. Traditionally the IT manager engaged in "technical" issues and had little understanding of business and organisational issues (Evans, 2003; Senn, 1995; Wyneknoop, 1995; Carusso, 1998). The changing role of the IT executive today requires knowledge and skills of the entire business domain and should be part of the strategic thrust of the business (Sawyer et al., 1998; Wang, 1995; Travis, 2002; Eckhouse, 2002).

On strategic alignment respondents commented that it is of paramount importance for the IT strategy to align itself to the business strategy, otherwise the company would not exist. Research has indicated that traditional alignment no longer provides business solutions (Dickson and DeSanctis, 2000; Smaczny, 2001). What is needed is fusion. This view was greatly supported by views from the industry that further support the literature findings. They felt that: 
Fusion between business and IS/IT entails a strategic, financial and operational integration between units. It will be necessary for these units to remain objective towards each other and maintain synergy towards achieving common goals. There should be constant communication between units to stimulate new ideas that will result in greater productivity.

Business and IT "must function as an integrated whole and both parties must operate in unison, understanding the needs of the one and the capabilities of the other". It was further iterated that to create the necessary fusion, "joint development on an IT vision and building trust between the parties involved based on a proper service level agreement” are necessary. This view is supported by authors such as Luftman (2000); Britt (2002); Eckhouse (2002) and Wang (1995).

\section{What constitutes fusion?}

From the literature review and the results of the questionnaires and interviews, it is clear that there is fusion between the IT function and the rest of the business if the following criteria are met:

- The IT department and the business client have the same goals.

- Both the business and IT representatives take responsibility for project success.

- Users are involved in the problem definition, planning and design process.

- The IT function solves the real business need, not only what they perceive as the need.

- Business clients and IT professionals understand each other's worlds and speak a common language.

- Business clients and IT professionals have realistic expectations of the other's performance.

- Clear communication between the parties.

- Effective documentation.

- Effective and timely testing, involving the client.

- Interpersonal relationships are based on trust, empathy and mutual respect.

- The business strategy and the IT strategy are developed to support each other.

- Knowledge transfer from one project to the next.

- Management involvement and good leadership - that is supportive of change and technological advancement - on both top management and project management levels.

- An organisational culture that is supportive of technology.

- IT leaders who understand and accommodate the unique characteristics of the IT environment.

\section{Promoting fusion through $O D$}

The second research question addresses the question of how the IT executive could contribute towards fusion fulfilling an OD role? From the results of the first research question it is already clear that there is consensus between literature and industry with 
regard to the factors influencing the IT-business interface. It is therefore proposed that it is the organisational development role in particular that can contribute in the creation of the desired IT-business fusion.

It is clear that the most important issues surrounding fusion lie within the domain of OD issues, namely:

- improved communication;

- address people, behavioural and cultural issues;

- a strong focus on interpersonal relationships;

- change negative attitudes;

- emphasise on the strategic role/involvement of managers/leaders;

- improve skills, attributes and attitudes of IT personnel;

- $\quad$ promote effective knowledge transfer between IT and the business; and

- apply effective leadership principles on all levels of responsibility.

Organisations of the twenty-first century are profoundly affected by technological advancement. Mutsaers et al. (1998) believe:

[...] the benefits of IT deployment are marginal if only superimposed on existing organisational conditions. Thus benefits accrue in those cases where investment in IT functionality accompany corresponding change in organisational characteristics.

O'Connor and Smallman (1995) supports this by saying that:

[...] capitalising on IT requires something more fundamental than merely changing a corporation's structures, business processes and strategy. It requires individuals to change their behaviour. They must change what they do, how they do it, how they work with each other and how they work by themselves.

The issues can therefore be closely linked to organisational development responsibilities and the need for interventions. When designing trials of interventions to change professional practice in the IT industry, choices have to be made about the selection of appropriate practices, development and adaptation of interventions and experimental design.

\section{The OD role of the IT executive}

For OD to work, IT executives must believe that people are important and by bringing out the best in people will organisations reach optimal effectiveness and increase profits. According to Appelbaum (1997) "integrating organisational development and technological intervention into a total system is one of the more difficult tasks for an executive or consultant to execute". As organisations are affected by technological advancements, they require a flexible customised change model. This requires expertise and judgement in social, technological and systems theory and practice. It seems clear 
that the IT executive who refuses to face the reality of his/her changed role and what is now expected of him/her, will inevitably be sidelined (Cummings and Worley, 2001).

According to Coghlan and Hurley (1996), the IT executive is the one high-level manager who is involved in all aspects of an organisation, and who has a real helicopter view of the organisation and its activities. IT executives need to think big to determine how IT can best support business goals and help the company gain a competitive advantage. As the traditional role of the IT executive was far more technical and removed from the other spheres of business, the lack of alignment, integration, and co-operation with the rest of the organisation resulted in the failure of many IT projects and systems (Mann, 2002; Bradshaw-Lynn, 1999, Du Plessis, 2003). Fulfilling an OD role will enable the IT executive to be a valuable partner, advisor and a strategic contributor that can help drive business goals, improve growth and create lasting advantage (Evans, 2003; Britt, 2002; Kuruppuarachichi et al., 2002; McNamara, 1999).

The study of the reasons why IT projects fail and the adverse relationship between IT and business indicated that there are a number of social problems that must be addressed before an IT executive can be effective in organisational development. An important category of relationship issues, as indicated by IT managers in the survey, is people, behavioural and cultural issues. This includes resistance to change, power play and leadership gaps. The most challenging issues in IT today are not about technology or systems; nor are they about the use of information. They are about the styles and behaviours of many IT professionals (Coghlan and Hurley, 1996). Many IT executives are still unaware of the many human organisational factors that can be attributed to project failure (Mann, 2002; Logan 2002; Cormack, 2001). Senior managers in particular are criticised for their lack of understanding of the links between technical and organisational issues.

- Managers often perceive their staff as costs rather than investments, as units of production, and as sources of error and unpredictability. They place too much emphasis on cost reduction and rapid payback.

- Organisational and managerial practices are characterised by high levels of fragmentation and differentiation, and by associated political concerns: together these make co-ordinated effort very difficult to manage.

- Managers and organisations are prone to the latest fads and fashions.

The modern organisation is a highly political environment and IT people need to be equipped to deal with the situations that face them (Wynekoop and Walz, 1999; Wyneknoop, 1999). IT executives have to take a holistic perspective on IT-related organisational change. OD must be integrated into both strategic and everyday IT operations and decisions. A number of important OD skills will equip the IT executive to play a role in promoting fusion between the IT function and the rest of the business:

1. Change management. The implementation of IT projects, especially large projects, is synonymous to change management in an organisation, either for gaining competitive advantage or for altering the work culture. Change presents 
both risk and opportunity, which is why people both seek and fear change. One of the most important reasons for IT/IS project failure - according to both IT and business managers - is that people resist change because they do not want to leave their comfort zones. People change management, aimed at achieving acceptance of IT systems, is therefore a major challenge for IT executives (Harvey, 1997; Nielsen et al., 1999; Kuruppuarachichi et al., 2002; Mutsaers et al., 1998; Venkatraman, 1994).

2. Development and training. Many of the issues that were identified by IT and business managers as barriers to a good business-IT relationship were focused on the individual. Factors such as taking responsibility, "connecting energies" to move in the same direction, pressure and stress management, and communication skills are absent in many organisations. These views are supported by authors such as Mann (2002), Whittaker (1999), Callon (1996) and Fielding (2002)IT executives move to the role of manager . through a technical career, which involves working with computers more than with humans. The role of the IT executive is technical in nature, thus IT executives are stereotyped as lacking in flexibility and the ability to work with ambiguity. Patching and Chatham (1998) refers to IT executives as "politically naïve". They should refocus on themselves as people and away from their roles as IT executives. Managers must be trained to understand what motivates employees, so they can manage them in ways that encourage innovation, improve productivity and meet strategic goals. IT managers therefore have to be trained to deal with employees who resist goals they did not help set. They should acknowledge if they have not acquired good people skills, and recognise that such skills are vital (Logan, 2002; Kunda and Brooks, 2000). The personal development areas for IT executives are cognitive skills, self-knowledge, the ability to manage their emotions and personal drive (Bradshaw-Lynn, 1999).

3. Motivating and empowering others. IT employees must feel they control their own destiny if they are to be part of a change process, provide excellent service or take risks. Melymuka (2003) suggests that motivating people who deliver technology is different and traditional power is useless, because:

o The people are different:- they are often more loyal to technology than they are to the manager;- they have a constant need for things to make sense; and- they ignore official hierarchies and create their own.

o The work is different:- failure occurs frequently; and- subordinates often know more than their managers about the job.

Unrealistic project completion dates, coupled with continually changing requirements, users who do not know what they want, a lack of consistent and clear definition of the problems, high expectations in the face of limited resources and application complexity, were all mentioned by survey participants as major contributing factors toward IT/IS system failure. This is in line with the views of Mann (2002), Katz and Tucker (1995), Britt (2002)An effective IT leader will establish the . objective, clarify the limits of authority and autonomy and enable individuals to take responsibility for achieving the objectives in their area. This 
will create a climate in which both business and IT employees want to be involved and be totally committed to achieving the overall corporate goal.

4. Coaching. IT managers rated "not enough emphasis on soft skills in the IT function" as a significant factor in business-IT relationship problems. Lash and Sein (1995) noted that the requirement for the IT professionals are becoming more demanding in multiple dimensions, particularly in the areas of business functional knowledge, interpersonal and management skills. These types of skills are not typically part of the curriculum of IT student and other means will have to be used to acquire these skills (McClean, 1996; McGuire and Randall, 1998, Evans, 1999). Coaching could be used to address both types of problems to help employees improve their personal performance.

5. Job design and work setting. For the past number of years, the high turnover of IS/IT staff (amplified in South Africa by the brain drain to other countries) has lead to discontinuities and the inability to attract and retain IT/IS resources with the required skills set (Aggarwal and Rezaee, 1996). The IT executive can attract good employees and provide a meaningful workplace for staff members by designing individual job tasks fit for the purpose of acquiring the desired skill sets by:

o challenging them to achieve;

o recognising worthwhile work;

o accepting the strengths and weaknesses of every individual;

0 building a sense of bonding and community;

0 being sensitive to their needs (i.e. care for and spend time with their families); and

o treating employees with equality, justice and fairness.

6. Job enrichment. The fact that IT skills become obsolete in a short period of time has always been a problem in the fast-changing ICT industry. This is a contributing factor to the problem of finding and retaining employees with the required technical skills. Job enrichment across disciplines should be an effective method of bridging the gap between business units and the IS/IT function through knowledge transfer, mutual understanding, similar perceptions of what makes a good system and a common vocabulary - all factors regarded by both businessand IT managers as among the most important issues in the business-IT relationship.

7. Succession planning. Finding and keeping technical professionals is not easy. In the financially competitive and technologically advanced business world technical professionals are in great demand. The high turnover in the IT industry turns succession planning into an important focus area for the IT executive. When somebody leaves a company the company has to replace the individual, often from the outside. It could take long for a new employee to become productive. Such a lack of continuity has a negative impact on the productivity and competitiveness of an organisation. Employees who have been trained in more than one aspect of the business can play a major part in such a transition period.

8. Organisational learning. The IT industry is a knowledge-intensive environment. An important responsibility of IT executives is therefore to manage the 
organisational knowledge and develop the knowledge workers towards a learning organisation. One of the most important problems in the business-IT relationship, as identified by the survey, is the lack of knowledge transfer so that the person in IT gains knowledge of the business issues and can think of IT in the context of the business, and vice versa for business people. In many organisations people move to different projects without transferring to their successors the knowledge they gained and the lessons they learnt from past mistakes. IT executives should be educated to be involved in OD interventions, in stead of relying on training alone to create and transfer knowledge.

9. Communication. During the survey the IT managers ranked "lack of communication between IT and business" as the most important out of 25 categories, while business managers ranked it second. Participants agreed unanimously that at the heart of the communication problem is the fact that business users understand their business at the business process level, while developers understand it in terms of data structures, etc. Furthermore, they agreed that clear communication processes between business and IT is a major problem in the relationship (Mann, 2002; Whittaker, 1999; Callon, 1996; Fielding, 2002An important responsibility of IT executives ). is to manage the internal communication with employees, including job-specific information and essential organisational information. Effective internal communication also contributes to the successful implementation of change management programmes.

10. Culture change. Organisations should realise that there is a cultural difference between business experts and IT professionals, which often leads to an adverse relationship between the two parties. IT executives have to focus on the human element of IT and the cultural differences between business and IT groups, and then take steps to bridge the differences. If the assumptions, beliefs and normal behaviours of all employees in an organisation were aligned, they would result in an organisational culture with many success stories.

11. Interpersonal relationship management. Interpersonal relationship management is based on communication, trust and respect. Literature (Logan, 2002; Fielding, 2002) refers to "adverse relationships", "rivalry" and "us versus them mentality". Although the category IT management problems was not rated high overall, both business and IT managers agreed that IT executives "do not take up the responsibility to bridge the relationship gap between IT and business". In the information age we live in today, it is vital that IT employees work effectively with the rest of the business. An IT executive must manage satisfaction from multiple perspectives at once in a way that other executives do not (for example the chief executive officer (CEO) and the board of directors, external consultants, vendors, service providers, customers and suppliers).

12. Strategic interventions. According to Britt (2002), one of the most important prerequisites for achieving fusion in an organisation is equal involvement of business and the IS/IT function in strategy and business design. The IT executive is no longer a technocrat who keeps computer systems running, but is more likely to be a business-savvy strategic player who is also involved in planning, product development and sales and marketing. The survey results indicate that both IT and business managers regard "lack of strategic alignment between IT and business" 
as an important contributing factor towards the relationship gap. IT executives also indicated that they are often not part of the strategy formulation team/board of directors, as is suggested by Travis(2002). Results indicated that IT managers often have a feeling of being left out in the dark, not knowing where business is heading, and what the organisation expects from IT. The involvement of the IT executive in strategic planning is important as s/he can make a significant contribution towards integrating IS/IT into the overall strategy of the organisation.

\section{Summary and conclusions}

This research focused on the business-IT interface and aimed to investigate the gap between the business and the IS/IT function, and to describe the role of the IT executive in promoting business/IT fusion. The results indicated that the research findings support the perspectives of the leading authors in the field. The research further indicated how the role of OD could create IT-business fusion.

A review of the literature and empirical studies indicated that the traditional model of strategic alignment is not enough to close the gap. A linear process of creating the business strategy with the IT strategy following it is not enough to ensure successful IT implementations. The strategic alignment model therefore no longer provides companies with the correct answers to the problems in a fast-changing environment such as information communication technology (ICT). A new approach is needed - a higher level of alignment, also termed fusion by a few researchers and practitioners. Such fusion has to be achieved on all levels of the organisation (strategic, tactical and operational).

Fusion between the customer (client/end user) and the IT professionals will only materialise if:

- The needs of the client are solved by means of an IT implementation. For this it is necessary that the real need is identified and documented properly before the solution is designed, coded and implemented.

- Successful ongoing "partnerships" are forged between IT and business units, as are interpersonal relationships between the various stakeholders in the IT/business relationship. This would lead to a learning organisation where the user and the technical specialist understand each other's world and share responsibility for the success of IT implementations. Such healthy relationships would lead to greater customer value and profitability.

There are a number of important role-players responsible for the creation of fusion, of which the IT executive is an important one. The role of the IT executive is changing, requiring special leadership capabilities and a more participative, people-oriented style. In return, business must treat IT as both a creator of value and an important player in the design of the organisation's strategy.

The radical organisational change is extending the responsibility for OD beyond the external OD consultant to functional managers who combine these responsibilities with 
their existing operational, professional or technical roles. By integrating the OD and IT role, the IT executive will be able to achieve synergy between business and IT leading to greater organisational effectiveness and utilisation of resources.

\section{Limitations of the study}

Owing to the large number of IT-related industries and geographic constraints, only companies in Gauteng region, which is considered as the economic heart of South Africa, have been included in the study. The small sample size might hinder the generalisation of the results and could be further extended. Many of the issues have only be touched on and needs further exploration.

\section{Future research}

The research includes aspects from many different disciplines and serves as a starting point for a body of knowledge regarding the role players in the business/IT interface. Identification of the issues will open up many research opportunities. Possible areas for future research are:

- developing a measuring instrument for fusion in the business/IT interface;

- a business strategy to promote fusion;

- fusion within the IT function (internal fusion); and

- role clarification and the development of business/IT role players.

\section{References}

Aggarwal, R, and Rezaee, Z. (1996), "Total quality management for bridging the expectations gap in systems development", International Journal of Project Management, Vol. 14 No. 2, pp. $115-20$.

Appelbaum, S.H. (1997), "Socio-technical systems theory: an intervention strategy for organisational development", Management Decision, Vol. 35 No. 6, pp. 452-63.

Britt, F.F. (2002), Multiplying Business Value: The Fusion of Business and Technology, IBM Institute for Business Value, White Plains, NY.

Callon, J.D, (1996), Competitive Advantage through Information Technology, McGraw-Hill, New York, NY.

Coghlan, L. and Hurley, M. (1996), "A profile of the information technology executive". Information Management, Computer Security, Vol. 4 No. 1, pp. 5-9.

Correia, EJ. (2002), "VDC: project failure rates", available at: www.sdtimes.com 
Cummings, T.G. and Worley, C.G. (2001), Organisation Development and Change, 7th ed., South-western College Publishing, Belmont, CA.

Dickson, G. and DeSanctis, G. (2000), Information Technology and the Future Enterprise, Prentice-Hall, Englewood Cliffs, NJ.

Doyle, M. (2002), "From change novice to change expert", Personnel Review, Vol. 31 No. 4, pp, 465-81.

Eckhouse, J. (2002), "IT gets the business", available at www.optimizemag.com

Evans, A. (1999), The Knowledge and Information Technology (KIT) Worker in a Changing Environment and Its Impact on Technikon Information Technology Training Programs, Technikon, Pretoria.

Evans, A. (2003), "A framework for creating fusion in the business-IT interface", $\mathrm{PhD}$ dissertation, University of Pretoria, Pretoria.

Fielding, R. (2002), "IT projects doomed to failure", available at: www.computing.co.uk

Katz, M. and Tucker, J. (1995), "Forging good relationships", InformationWeek, No. 518, p. 96.

Kunda, D. and Brooks, L. (2000), "Human, social and organisational influences on component-based software engineering", Carnegie Mellon University, Pittsburgh PA, available at: www.sei.cmu.edu/cbs/icse99/papers/19/19.htm

Kuruppuarachichi, P.R., Mandal, P. and Smith, R. (2002), "IT project implementation strategies for effective changes: a critical review", Logistics Information Management, Vol. 15 No. 2, pp. 126-37.

Lash, P.B. and Sein, M.K. (1995), Career Paths in a Changing IS Environment: A Theoretical Perspective, SIGCPR, New York, NY.

Logan, J+ (2002), "Can't we all just get along?", Optimise Magazine, 9 July.

Luftman, J. (2000), Assessing IT/Business Alignment Maturity, School of Management, Stevens Institute of Technology, Castle Point on Hudson, Hoboken, NJ.

McClenahen, J. (2002), "CIO's soar to strategic role", industry Week Articles, available at: www. industryweek.com/CurrentArticles/asp/articles?ArticleID $=1296$

McGuire, E.G. and Randall, K.A. (1998), Process Improvement Competencies for IS Professionals: A Survey of Needs, ACM SIGCPR, New York, NY.

Mckendrick, J. (2000), "One small step for an IT executive, one giant leap for the economy", November, available at: www/findarticles,com

McNamara, C. (1999), "Holistic organisation development: a paradigm for the future", available at: www.mapnp.org/library/misc/new_OD.htm (accessed 11 March 2003).

Melymuka, K. (2003), "Premier 100: IT leaders learn how to get more out of their geeks", ComputerWorld, 25 February.

Miles, M.B. and Huberman, A.M. (1994), Qualitative Data Analysis, 2nd ed., Sage, London.

Murray, J.P. (2001), "Recognising the responsibility of a failed information technology project as a shared failure", Information Systems Management Journal, Vol. 18 No. 2.

Mutsaers, E., van der Zee, H. and Giertz, H. (1998), "The evolution of information technology", Informaliom Management \& Computer Securily, Vol. 16 No. 3, pp. 115-26.

Nielsen, S.H., von Hellens, L.A., Greenhill, A., Halloran, P. and Pringle, R. (1999), IT Degree Studies and Skills Development for Leaming Organisations, ACM SIGCPR, New York, NY.

O'Connor, G. and Smallman, C. (1995), "The hybrid manager: a review", Management Decision, Vol. 33 No. 7, pp. 19-28. 
Patching, K. and Chatham, R. (1998), "Getting a life at work: developing people beyond role boundaries", Journal of Management Development, Vol. 17 No. 5, pp. 316-37.

Riggle, M. (2002), "Breaking the cycle of failure", Intelligent Enterprise, 10 August, available at: www.intelligententerprise.com

Sawyer, S., Erschenfelder, K.R., Diekema, A. and McClure, C.R. (1998), “Corporate IT skill needs: a case study of BigCo", Computer Personnel, April, pp. 27-41.

Smaczny, T. (2001), "Is an alignment between business and information technology the appropriate paradigm to manage IT in today's organisations?", Management Deciston, ' Vol. 39 No, 10, pp. 797-802.

Trauth, E., Farwell, D.W., Lee, D. and The, I.S. (1993), "expectations gap: industry expectations versus academic preparation”, MIS Quarterly, Vol. 17 No. 3, September, pp. 293-307.

Travis, L. (2002), "An ECM strategy council drives the resolution of IT governance issues", AMR Research, available at: www.amrresearch,com

Venkatraman, N. (1994), "IT-enabled business transformation: from automation to business scope redefinition", Sloan Management Review, Vol, 35 No, 2.

Wang, C. (1995), Techno Vision II, McGraw-Hill, New York, NY.

Whittaker, B. (1999), "What went wrong? Unsuccessful information technology projects", Information Management \& Computer Security, Vol. 7 No. 1, pp. 23-9.

Wynekoop, J.L. and Walz, D.B. (1999), Characteristics of High-Performing IT Personnel: A Comparison of IT versus End-user Perceptions, ACM SIGCPR, New York, NY.

\section{Further reading}

Bargsley, A. and Mouth, P. (2002), "Investing in your employees", The CEO Refresher, available at www.refresher.com/abphinvesting.htmlwww.refresher.com/abphinvesting.html

Harvey, P. and Butcher, D. (1998), "Those who make a difference: developing businesses through developing individuals", Industrial and Commercial Training, Vol. 30 No. 1, pp. 12-15.

Henderson, J. and Venkatraman, N. (1990), "Strategic alignment: a model for organisational transformation via information technology", Working Paper, No. 3223-90, Sloan School of Management, MIT, Cambridge, MA.

King, W.R. (2001), "IT capabilities, business processes and impact on the bottom line", Information Systems Management Journal, Vol. 8 No. 2, p. 17.

McDonagh, J. and Coghan, D. (2000), "Sustaining the dilemma with IT-related change: the fortuitous role of academia", Journal of European Industrial Training, Vol. 24 No. 5 , pp. 297-304.

MeLean, E.R., Smits, S.J. and Tanner, J.R. (1996), "The career dynamics of information systems professionals: a longitudinal study", Computer Personnel, Vol. 17 No. 4, ACM SIGCPR, pp. 3-26.

Miller, F.A., Katz, J.H and Gans, R. (1998), "Becoming a worthy organisation", Journal of the Organisation Development Network, Vol. 30 No. 3.

Thite, M. (1999), "Identifying key characteristics of technical project leadership", Leadership \& Organization Developmenl Joumal, Vol. 20 No. 5, pp. 253-61. 